\title{
Thoracic full-endoscopic unilateral laminotomy with bilateral decompression for treating ossification of the ligamentum flavum with myelopathy
}

\author{
Yong-Peng Lin $^{1,2 \#}$, Rui Lin ${ }^{1 \#}$, Song Chen ${ }^{1}$, Si-Yuan Rao ${ }^{1}$, Shuai Zhao ${ }^{1,2}$, Tao Wen ${ }^{1,2}$, Hong-Shen Wang ${ }^{1,2}$, \\ Wei-Xiong $\mathrm{Hu}^{1,2}$, Bing-Xin Liu ${ }^{1}$, Xin-Yi Li ${ }^{1}$, Yong-Jin Li ${ }^{1,2}$, Bo-Lai Chen ${ }^{1,2}$ \\ ${ }^{1}$ Guangzhou University of Chinese Medicine, Guangzhou, China; ${ }^{2}$ Division of Spine Center, Guangdong Provincial Hospital of Chinese Medicine, \\ Guangzhou, China \\ Contributions: (I) Conception and design: BL Chen, YP Lin; (II) Administrative support: YJ Li; (III) Provision of study materials or patients: S Zhao, \\ T Wen, HS Wang, WX Hu; (IV) Collection and assembly of data: YP Lin, R Lin, S Chen, SY Rao, BX Liu, XY Li, S Zhao; (V) Data analysis and \\ interpretation: YP Lin, R Lin; (VI) Manuscript writing: All authors; (VII) Final approval of manuscript: All authors. \\ \#These authors contributed equally to this work. \\ Correspondence to: Bo-Lai Chen. Guangzhou University of Chinese Medicine and Guangdong Provincial Hospital of Chinese Medicine, 111 Dade \\ Road, Yuexiu District, Guangzhou 510120, China. Email: chenbolai@gzucm.edu.cn.
}

Background: The aim of the present study was to evaluate the curative effect and safety of thoracic fullendoscopic unilateral laminotomy with bilateral decompression (TE-ULBD) for treating ossification of the ligamentum flavum (OLF) with myelopathy.

Methods: Between January 2015 and December 2018, 23 consecutive patients with symptomatic thoracic OLF were treated with TE-ULBD. Of these, 21 (13 women and 8 men, aged 49-75 years) were included in the study and followed up for a minimum of 1 year. The mean blood loss was $15.48 \mathrm{~mL}(10-30 \mathrm{~mL})$, operative duration was $78.86 \mathrm{~min}$ (55-115 $\mathrm{min}$ ), and hospitalization was 5.05 days (3-15 days). The Japanese Orthopaedic Association (JOA) was used to evaluate spinal cord function, and the curative effect was defined by the JOA improvement rate. The area of OLF (AOLF), the maximum spinal cord compression (MSCC), and the area of spinal cord (ASC) were used to evaluate OLF clearance and spinal cord decompression status. Results: At the final follow up,the JOA score was 8.33 points (5-11 points), which was a significant improvement from the preoperative 5.33 points $(3-9$ points, $\mathrm{P}<0.01)$. The excellent and good rate was $76.19 \%(16 / 21)$. The average preoperative AOLF and AOLF ratio were $85.27 \pm 23.66 \mathrm{~mm}^{2}$ and $57.86 \% \pm 11.86 \%$, respectively, and the postoperative AOLF and AOLF ratio were $16.27 \pm 11.75 \mathrm{~mm}^{2}$ and $8.13 \% \pm 5.38 \%$, respectively. The MSCC increased from $27.99 \% \pm 13.51 \%$ preoperatively to $48.02 \% \pm 6.66 \%$ postoperatively. The ASC was $42.90 \pm 10.60 \mathrm{~mm}^{2}$ preoperatively and $64.54 \pm 21.36 \mathrm{~mm}^{2}$ postoperatively. There were statistically significant differences in all parameters preoperatively and postoperatively $(\mathrm{P}<0.01)$. One case had postoperative hematoma, and the symptoms gradually eased after 3 weeks of conservative treatment. There were no other complications. No recurrence of OLF was detected during the follow-up period.

Conclusions: TE-ULBD is safe and effective for thoracic OLF with the advantages of reduced trauma and bleeding, and faster recovery.

Keywords: Percutaneous endoscopic surgery; minimally invasive surgery; bilateral decompression; thoracic ossification of the ligamentum flavum (thoracic OLF)

Submitted Apr 06, 2021. Accepted for publication Jun 15, 2021.

doi: 10.21037/atm-21-2181

View this article at: https://dx.doi.org/10.21037/atm-21-2181

\footnotetext{
^ ORCID: 0000-0001-9322-8132.
} 


\section{Introduction}

Thoracic ossification of the ligamentum flavum (TOLF) is one of the most common pathogenetic causes of thoracic myelopathy $(1,2)$. Although its incidence is relatively low, the incidence of asymptomatic TOLF is about $3.8 \%$, thoracic stenosis with myelopathy caused by TOLF can be extremely serious (2-6). Because of ineffective outcomes with conservative treatment and the difficulty in neurological function rehabilitation for TOLF, operation is recommended as soon as possible to remove the spinal cord compression once patients have lower limb weakness or sensory disorders $(1,3,5-8)$. At present, commonly used surgical methods include posterior laminoplasty, hemilaminectomy, laminectomy with or without fusion, and transforaminal resection and decompression (5,6,9-11). Good therapeutic effect can be achieved by adopting these operative methods. However, these open procedures have deficiencies, such as severe trauma, excessive bleeding, and may even cause iatrogenic spinal instability. Li et al. recommended that TOLF surgery should use internal fixation to reconstruct stability and prevent progression of kyphotic deformity and associated neurological deterioration if the facet joint is excessively damaged during the operation (9). The use of internal implants is associated with high cost and the risk of other complications, such as pedicle screw breakage or displacement. Previously published studies have reported that the complication rate of TOLF surgery is as high as $35-51 \%(6,12-15)$.

In the past decade, percutaneous endoscopic surgery has been widely used in lumbar and cervical degenerative diseases, and is known to be an effective alternative to conventional open surgical procedures. A few clinical reports have also recently addressed the application of endoscopic surgery in thoracic disc herniation, stenosis, and OLF (16-21). However, most of the surgeries in the literature are endoscopy-assisted surgeries using a $6.9-\mathrm{mm}$ endoscope (17-21).

In the present study, we introduced a method of thoracic full endoscopic unilateral laminotomy with bilateral decompression (TE-ULBD) to treat OLF by using a large endoscope. The main advantage of this technique is the high security, the whole process is performed under full endoscopic visualization and continuous irrigation fluid, and the TOLF can be removed step by step. The optimized large endoscopic system can also enable the surgeon to obtain a better operation field and perform the surgery effectively and accurately. We present the following article in accordance with the STROBE reporting checklist (available at https://dx.doi.org/10.21037/atm-21-2181).

\section{Methods}

\section{Patient characteristics}

Twenty-three consecutive patients with symptomatic TOLF were treated with TE-ULBD between January 2015 and December 2018. X-ray, computed tomography (CT), and magnetic resonance imaging (MRI) examinations were performed preoperatively. The study was conducted in accordance with the Declaration of Helsinki (as revised in 2013). The present study as approved by the Ethics Committee of the Guangdong Provincial Hospital of Chinese Medicine (No.: YE2021-146-01), and written informed consent was obtained from all participants.

Twenty-one patients (13 women and 8 men, aged 49-75 years) were included in the study and followed up for a minimum of 1 year. The length of symptoms ranged from 5 to 120 months, with an average of 27.61 months. There were 16 cases with lower limb paresthesia, 15 with decreased muscle in the lower extremities, 7 with thoracoabdominal girdle sensation, 5 with bladder-bowel dysfunction, and 6 with back pain. The mean blood loss was $15.48 \pm 5.90 \mathrm{~mL}$ $(10-30 \mathrm{~mL})$, operative duration was $78.86 \pm 16.66 \mathrm{~min}$ $(55-115 \mathrm{~min})$, and hospitalization was $5.05 \pm 2.58$ days (3-15 days). Surgical segment distribution was 1 in T1/2, 1 in T2/3, 1 in T7/8, 3 in T9/10, 10 in T10/11, and 5 in T11/12. According to Sato's classification (7), there were 8 lateral-type cases, 7 extended type, 4 enlarged type, and 2 fused type. According to Ning's classification, all cases were circumscribed type (22) (Table 1).

Sato classified TOLF into 5 types based on the progression of the ligament ossification on the axial CT scan as follows: lateral type (ossification of only the capsular portion), extended type (extension of the ossification to the interlaminar portion, but the affected part is still thin), enlarged type (thickening of the ossification with anteromedial enlargement), fused type (fusion of the bilateral ossified mass at the midline), and tuberous type (nodular growth of the ossified mass anteriorly) (7). Ning et al. divided TOLF into circumscribed (ossification in 2 or fewer adjacent levels), continuous (continuous ossification in 3 or more levels), and intermittent (intermittent distribution of local or continuous ossification) types according to lesion distribution in sagittal MRI (23). 
Table 1 Patient characteristics

\begin{tabular}{|c|c|}
\hline Variable & Number \\
\hline Age (years) & $62.44[49-75]$ \\
\hline Sex (female/male) & $13 / 8$ \\
\hline Length of symptoms (month) & 27.61 \\
\hline Blood loss (mL) & $15.48 \pm 5.90$ \\
\hline Operative time (min) & $78.86 \pm 16.66$ \\
\hline Hospital stay (days) & $5.05 \pm 2.58$ \\
\hline \multicolumn{2}{|l|}{ Location of OLF } \\
\hline $\mathrm{T} 1 / 2$ & 1 \\
\hline $\mathrm{T} 2 / 3$ & 1 \\
\hline $\mathrm{T} 7 / 8$ & 1 \\
\hline $\mathrm{T} 9 / 10$ & 3 \\
\hline $\mathrm{T} 10 / 11$ & 10 \\
\hline $\mathrm{T} 11 / 12$ & 5 \\
\hline \multicolumn{2}{|l|}{ Morphologic classification } \\
\hline Lateral & 8 \\
\hline Extended & 7 \\
\hline Enlarged & 4 \\
\hline Fused & 2 \\
\hline Tuberous & 0 \\
\hline
\end{tabular}

OLF, ossification of the ligamentum flavum.

\section{Surgical technique}

The operation was performed in the prone position on a radiolucent table under general anesthesia. An anteroposterior radiograph as obtained with a syringe needle to confirm the incision level. After verification of the incision level, the superficial surgical site was marked just lateral to the midline spinous processes. A 1-cm skin incision was made, and the superficial fascia and deep fascia were cut. The obturator was then introduced and used to feel the inferior border of the upper laminae, the superior edge of the inferior laminae, and the medial point of the facet joint. Stepwise expansion tubes were used to extend the soft tissue. The beveled working sleeve was then inserted and expansion tubes were removed, and the endoscope system was introduced through the working cannula.

Further procedures were done under continuous visual control and irrigation through the intra-endoscopic working channel. The overlying soft tissue was coagulated with the radio frequency (RF) probe and removed with endoscopic forceps to expose the anatomical structure of the lamina, intervertebral space, spinous process root, and articular process. Once the osseous structures were exposed, the lower border of the superior lamina was drilled until the attachment of the ligamentum flavum was exposed, and the drill was directed laterally toward the facet joint. The upper boundary of the inferior lamina and articular processes on the same side were excised, and the basal part of the spinous process was excised by high-speed drill until the normal boundary of the ligamentum flavum was clearly revealed.

Starting from the position where the yellow ligament is connected to the lamina or from the medial margin of the facet joint to explore the normal ligamentum flavum which is not yet ossified, the normal ligamentum flavum is removed by forceps and punches until the ossification of the ligamentum flavum (OIL) is revealed. The TOLF was then ground using layer-by-layer thinning by an endoscopic high-speed drilling system. Remanent laminae of the OLF were removed by endoscopic Kerrison punches. Finally, the over-the-top technique was used to decompress the contralateral margin of the spinal cord, which was then extended to the cranial and the caudal side (Figure 1). We again checked for any compression on the spinal cord and then exited the working channel. The wound was bound with tissue biological glue. Drainage tubes and antibiotics were not required. Patients were able to get of bed 6 hours after surgery and discharged the following day.

\section{Follow up and evaluation index}

The Japanese Orthopaedic Association (JOA) thoracic spine 11-point method was used to evaluate spinal cord function preoperatively, and at the 6-month, 1-year, and final follow up as follows: improvement rate $=($ postoperative $\mathrm{JOA}$ score - preoperative JOA score $) /(11$ points - preoperative JOA score) $\times 100 \%$. The curative effect was defined by the improvement rate as follows: excellent: $>75 \%$, good: $51-$ $75 \%$, intermediate: $25-50 \%$, and poor $<25 \%$. Intraoperative and postoperative complications were analyzed.

\section{Radiographic parameters and measurements}

CT and MRI scans with whole-spine $\mathrm{T}_{2}$-weighted images were taken. The picture archiving and communication systems (PACS) was used for measuring and collecting the MRI and CT scan data. Two observers with more than 
A

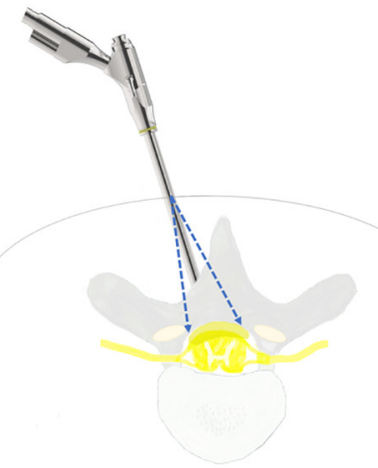

B

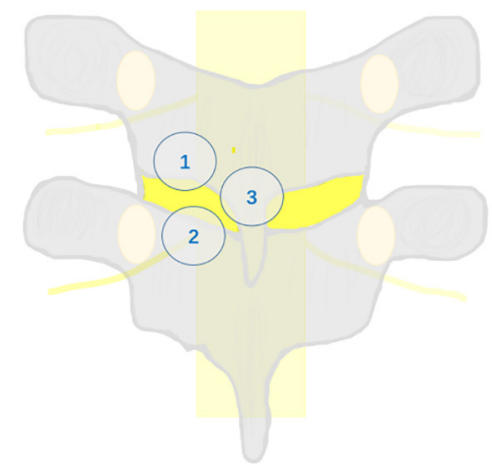

C

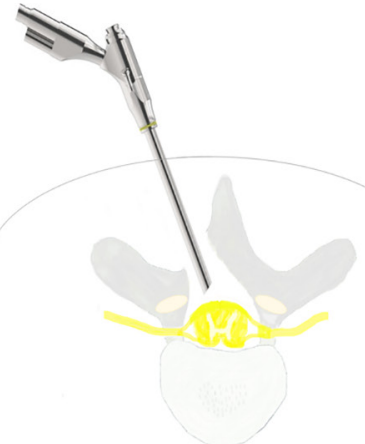

Figure 1 Schematic diagram of thoracic full-endoscopic unilateral laminotomy with bilateral decompression for ossification of the ligamentum flavum. (A) Endoscope is placed on the lamina of the surgical segment (blue dashed arrow indicates the range of decompression). (B) Order of the full-endoscopic lamina resection was as follows. The lower half of the upper lamina was removed, followed by the upper half of the lower lamina and the base of the spinous process. (C) Over-the-top technique to decompress the contralateral margin of the spinal cord and then extend it to the cranial and the caudal side.
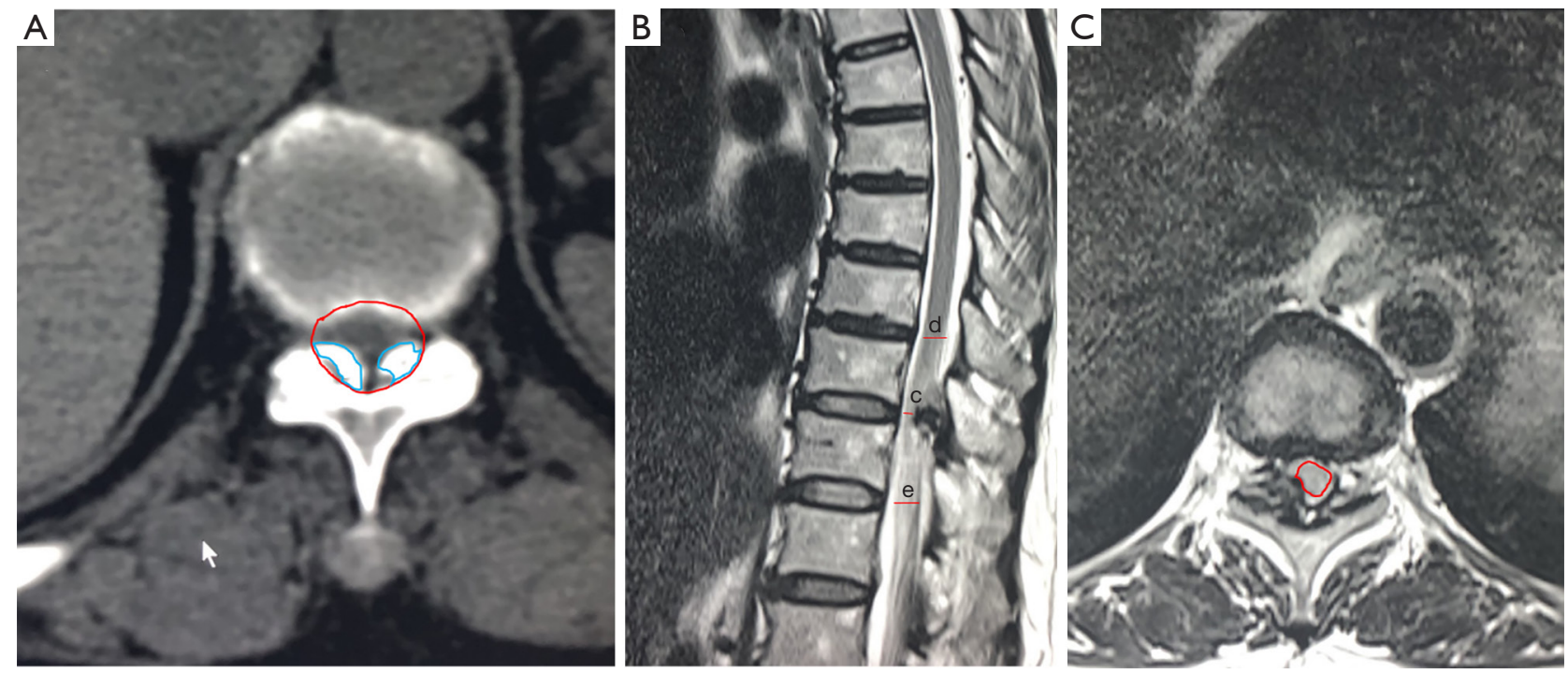

Figure 2 Imaging measure index. (A) Area under the ossification of the ligamentum flavum (AOLF) (blue) (a) and the canal area (red) (b). $\mathrm{AOLF} \%=\mathrm{a} / \mathrm{b} \times 100 \%$. (B) Maximum spinal cord compression $=\mathrm{c} /[(\mathrm{d}+\mathrm{e}) / 2]$. (C) Visual method of measuring the cross-sectional area of the spinal cord (red).

5 years of experience each in the spine field independently measured the area of the spinal cord (ASC) and spinal canal. In the PACS, the observers used the "measure 2D line segment" tool to measure the irregular shape area. The value of the measured index was automatically displayed. The area of the OLF (AOLF) and AOLF ratio were measured on CT, whereas the maximum spinal cord compression (MSCC) and the ASC were measured on MRI.

The AOLF was measured as the cross-sectional area of the OLF at the thickest point of the CT in the axial view. The AOLF ratio was measured as AOLF/canal area $\times 100 \%$. For better measurement and comparison, the canal area was measured as the cross-sectional area where the distance between the vertebra and lamina is shortest (Figure 2A) (1). 
The MSCC was defined as the ratio of the mid-sagittal diameter of the spinal cord at the compression site, which was divided by the average diameter of the spinal cord at the closest non-compressed regions (Figure 2B) (24). The ASC was measured as the cross-sectional area of the spinal cord at the compression site in the axial view of the $\mathrm{T}_{2}$-weighted image (Figure 2C) (25).

\section{Statistical analysis}

Statistical analysis was performed using SPSS (version 19.0; SPSS, Chicago, IL, USA). Comparisons of the clinical and radiologic data before and after surgery were performed using paired sample $t$-test. $\mathrm{P}<0.05$ was considered statistically significant.

\section{Results}

At the final follow up, the JOA score was 8.33 points (5-11 points), which was a significantly improvement from the preoperative 5.33 points $(3-9$ points, $\mathrm{P}<0.01)$ (Table 2); $56.25 \%$ (9/16) of lower limb paresthesia was completely relieved, $40 \%(6 / 15)$ of decreased muscle in the lower extremities fully recovered, $60 \%(3 / 5)$ of bladder-

Table 2 Comparison of Japanese Orthopaedic Association (JOA) scores before and after surgery

\begin{tabular}{lc}
\hline Variable & JOA scores \\
\hline Preoperative & $5.33 \pm 1.52$ \\
6 months postoperative & $7.05 \pm 1.24^{\star}$ \\
1-year postoperative & $7.86 \pm 1.28^{*}$ \\
Final follow up & $8.33 \pm 1.62^{*}$ \\
\hline
\end{tabular}

${ }^{*}$, compared with preoperative, $\mathrm{P}<0.01$. bowel dysfunction returned to normal, $71.43 \%(5 / 7)$ of thoracoabdominal girdle sensation completely disappeared, and all the back pain resolved (6/6). The JOA improvement rate was $61.5 \%(20-100 \%)$. Efficacy determination was as follows: 9 cases were excellent, 7 cases were good, and 5 cases were medium; the excellent and good rate was $76.19 \%$ $(16 / 21)$.

The average preoperative AOLF and AOLF ratio were $85.27 \pm 23.66 \mathrm{~mm}^{2}$ and $57.86 \% \pm 11.86 \%$, respectively, and the postoperative AOLF and AOLF ratio were $16.27 \pm 11.75 \mathrm{~mm}^{2}$ and $8.13 \% \pm 5.38 \%$, respectively. The MSCC increased from $27.99 \% \pm 13.51 \%$ preoperatively to $48.02 \% \pm 6.66 \%$ postoperatively. The ASC was $42.90 \pm 10.60 \mathrm{~mm}^{2}$ preoperatively and $64.54 \pm 21.36 \mathrm{~mm}^{2}$ postoperatively. There were statistically significant differences in all parameters preoperatively and postoperatively (Table 3).

One patient had symptoms of exacerbation of lower extremity radiation pain after surgery, but muscle strength of the lower extremity did not decrease. Hematoma was diagnosed by MRI examination. The patient underwent 3 weeks of treatment, and the symptoms gradually eased. The hematoma disappeared after 6 months. In addition, there were no complications, such as spinal cord injury, cerebrospinal fluid leakage, wound healing disorders, infections, deep venous thrombosis, or deteriorating neurological function. No recurrence of OLF was detected during the follow-up period.

\section{Discussion}

\section{TOLF classification and surgical options}

Although $\mathrm{T}_{2}$-weighted sagittal MRI is important for assessing the degree of spinal cord compression, CT scan is the most important method to diagnose and evaluate

Table 3 Comparison of radiographic parameters preoperatively and postoperatively

\begin{tabular}{lccc}
\hline Variable & Preoperative & Postoperative & P value \\
\hline AOLF $\left(\bar{x} \pm \mathrm{S}, \mathrm{mm}^{2}\right)$ & $85.27 \pm 23.66$ & $16.27 \pm 11.75$ & 0.000 \\
AOLF ratio $(\%)$ & $57.86 \pm 11.86$ & $8.13 \pm 5.38$ & 0.000 \\
MSCC $(\%)$ & $27.99 \pm 13.51$ & $48.02 \pm 6.66$ & 0.024 \\
ASC $\left(\bar{x} \pm \mathrm{S}, \mathrm{mm}^{2}\right)$ & $42.90 \pm 10.60$ & $64.54 \pm 21.36$ & 0.017 \\
\hline
\end{tabular}

Data presented as means \pm standard deviations. AOLF, cross-sectional area of the ossification of the ligamentum flavum at the thickest point; ASC, cross-sectional area of the spinal cord at the compression site; MSCC, ratio of the mid-sagittal diameter of the spinal cord at the compression site. 

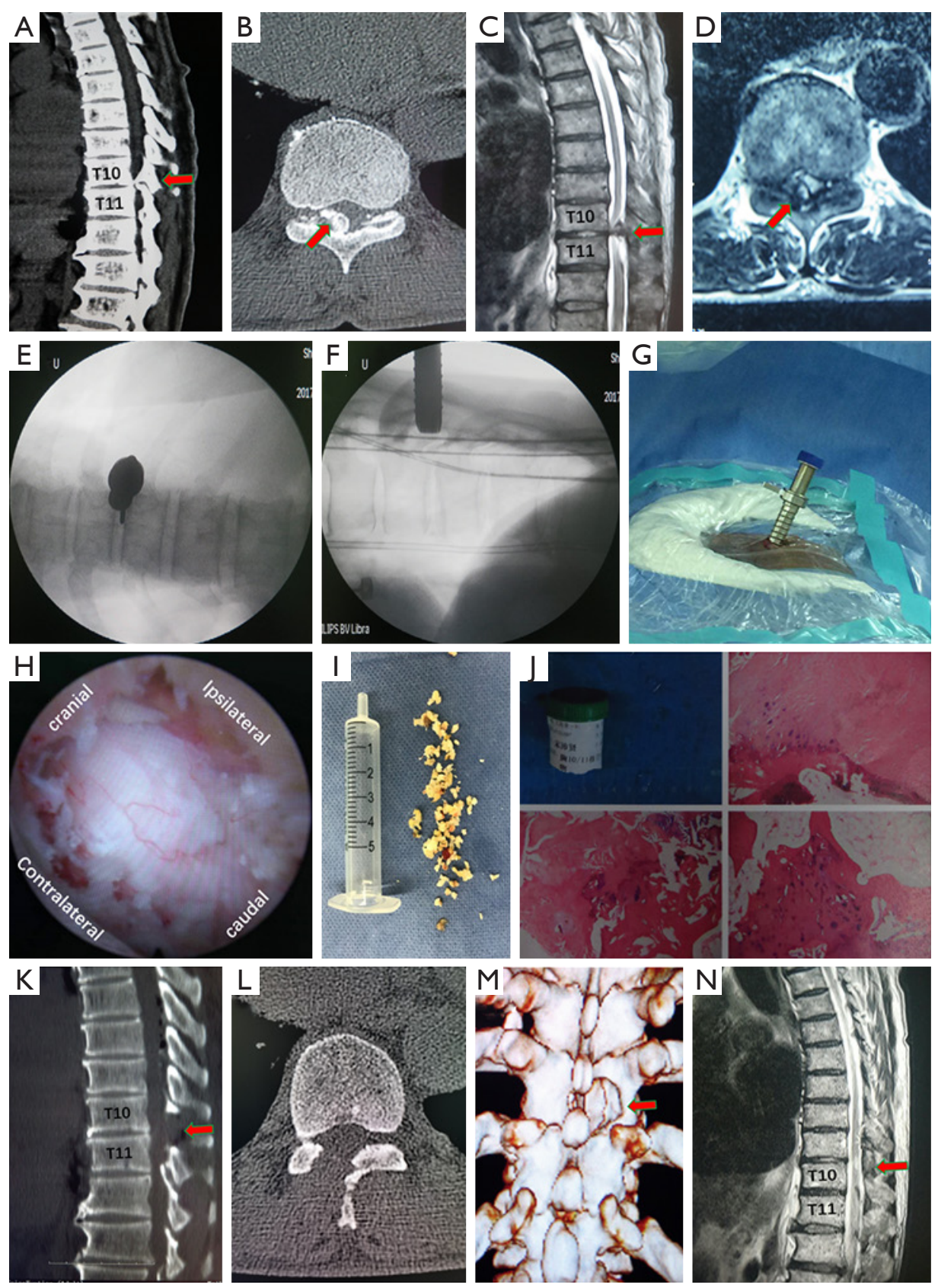

Figure 3 Case presentation. A 63-year-old male patient diagnosed with thoracic ossification of the ligamentum flavum (TOLF) at T10/11. (A) Preoperative sagittal computed tomography (CT) scan revealed that the OSF invaded the entire spinal canal and was attached to the posterior margin of the vertebral body. (B) CT scan in cross-section indicated lateral-type TOLF. (C) Preoperative sagittal magnetic resonance imaging (MRI) revealed severe spinal canal stenosis and obvious spinal cord compression at T10/11. (D) Right-side thickening of ligamentum flavum was more severe than the left. (E) Anterior-posterior X-ray revealed that the working channel was located at the junction of the lamina and articular process. (F) Working channel was located on the lamina surface on lateral X-ray. (G) Working channel of the 10$\mathrm{mm}$ endoscopic system. Its surface is a thread design, similar to a screw. (H) After complete decompression, the spinal cord was fully dilated, and could fluctuate gently without effort. (I) Intraoperative fragments of the TOLF. (J) Excised pathological tissue was confirmed as OLF by histopathological examination. (K,L). Postoperative CT scan showed that the OLF had been completely resected. (M) 3D CT showed that the enlarged bony window did not exceed half of the articular process. (N) MRI 2 years postoperatively revealed complete decompression of the spinal cord. Red arrows indicate surgical site. 
TOLF, because it can show precisely the areas where there is protruding ossification from the posterior to the anterior aspects of the spinal canal. The combination of CT scan and MRI can conduce to improve the accuracy of radiologic diagnosis for ossification of ligamentum flavum with thoracic myelopathy. TOLF typing is performed mainly by referring to the different manifestations of CT scan and MRI.

The choice of surgical modality should be based on the pathological factors of spinal cord compression, number of narrow segments, and the patient's systemic conditions. However, for TOLF with different pathological manifestations, no consensus has been reached on the selection of surgical method. Because the spinal cord is compressed from the posterior side, TOLF relief is mainly achieved by thoracic posterior wall resection and decompression. There are several options for treating TOLF, such as laminotomy, laminoplasty, foraminotomy, and en bloc laminectomy with or without dural excision/ floating ossified dura mater $(5,8-10,12,13,22,26-28)$. Open surgery has an inevitable disadvantage of further damage to the paraspinal soft tissue. Therefore, an accurate and minimally invasive decompression method according to the classification of pathological factors is a more reasonable solution. According to Ikuta et al. and Baba et al., a microendoscopic technique is also a feasible treatment for thoracic myelopathy caused by TOLF $(29,30)$. Some scholars used percutaneous endoscopic surgery to treat TOLF obtained satisfactory short-term clinical results $(29,30)$.

\section{Indications and contraindications of TE-ULBD}

Although percutaneous endoscopic surgery is a minimally invasive solution for the treatment of OLF, it is necessary to grasp the indications to obtain a better effect. Indications of TE-ULBD for TOLF are as follows: (I) progressive myelopathy symptoms (loss of vibration and proprioception, spastic paraparesis, or loss of sensation) with or without local thoracic pain. CT scans can indicate OLF, and MRI can show thoracic spinal stenosis and compression of the spinal cord; (II) 1 level or 2 levels; and (III) lateral type, extended type, enlarged type, and fused type, according to Sato's classification, and circumscribed type, according to Ning's classification.

Contraindications of TE-ULBD for TOLF are as follows: (I) tuberous type, according to Sato's classification, and circumscribed type or continuous type, according to Ning's classification; (II) ossification of the posterior longitudinal ligament, or intervertebral disc herniation with calcification; (III) high-grade deformity or prior history of surgery in the target segment; and (IV) spinal stenosis caused by tumor or fracture. This option is also not recommended in cases of segmental instability.

\section{Clinical outcomes and complications of TE-ULBD for TOLF}

Unlike open surgeries or the micro-endoscopic technique, full endoscopic surgery is performed under continuous irrigation fluid for clearer vision and reduced bleeding. Liu et al. performed percutaneous endoscopic surgery using the bilateral translaminar osseous channel approach to treat thoracic OLF combined with disk herniation, and obtained sufficient decompression of the spinal cord with minimum trauma (16). Wu et al. adopted endoscopic visual trepan decompression to treat single-segment OLF and found that it had advantages of reduced trauma, faster recovery, and lower cost than the technique of posterior spinal canal resection and decompression (17). An et al. adopted percutaneous full endoscopic posterior decompression for the treatment of TOLF at a single level and obtained satisfactory clinical results. They found that endoscopic surgery is a safe, effective, and reliable method for OLF (18).

Based on the results of the cases in the present study, interoperative blood loss was $15.85 \mathrm{~mL}$ and no postoperative drainage was needed, and hospitalization was 5.14 days. These results are significantly lower than those reported in the literature for open surgery $(18,31)$. The postoperative JOA was significantly increased, which means that the patient's neurological function and motor function are significantly improved. The postoperative AOLF, AOLF ratio, MSCC, and ASC were significantly improved compared those preoperatively, indicating that TE-ULBD can effectively remove OLF and fully decompress the thoracic spinal cord (Figure 3). In addition, TE-ULBD did not have serious complications, with only 1 case of postoperative hematoma found. The complication rate was $4.76 \%$, which is lower than that reported in the literature for other surgeries (11.11-23.33\%) (18). According to reports in the literature, the most likely complications of endoscopy assisted surgery for TOLF include: Dural tears, transient paraesthesia or neuralgia, revision surgery, neurological injury and epidural haematoma (16-20,32).

\section{Technical essentials of TE-ULBD}

Thoracic decompression may seem simple, but serious 
postoperative complications, such as aggravation of spinal cord injury, are still common occurrences. The blood supply of the thoracic spinal cord is consistent with the distribution of spinal nerves. There is only a few vascular anastomosis branch of the thoracic medulla, and its collateral circulation blood supply capacity is poor, so that it is prone to ischemia. The high thoracic and thoracolumbar segments of the spinal cord are transitional regions with different blood supplies and are prone to ischemic injury. However, thoracic spinal canal volume is low, and the medulla spinalis has poor tolerance to oppression. Therefore, excessive traction of the spinal cord during surgery, or compression of nerves by surgical instruments, as well as damage to the peridural vascular network, may lead to deterioration of postoperative nerve function. We recommend endoscopic layer-by-layer thinning technique to treat TOLF, which can remove OLF without extra pressure to the spinal cord and reduce the harmful stimulation to the spinal marrow.

The epidural space is rich with blood vessels that may easily beget of bleeding and cause the blurred vision during surgery. The drawback of open surgery is that when there is excessive intraoperative bleeding, hemostasis will be difficult, which may lead to residual TOLF and postoperative hematoma. We recommend using prehemostasis measures to control bleeding, if the venous plexus around the epidural sac will obstruct further operation, it can be cauterized by radiofrequency before rupture. Endoscopic pre-hemostasis does not only reduce bleeding but can also reduce the blurred surgical field of vision after bleeding and increase the safety of operation.

Thoracic decompression should cover holo-laminectomy and half of the articular processes at the transverse level and should exceed 1 segment of the compression level in the coronal $(6,8,10,14)$. To confirm the effectiveness of the operation, the ossified ligamentum flavum should be completely removed under the endoscope, and the spinal cord should fully decompressed. We believe that the scope of decompression can be confirmed if the spinal cord is fully expanded under endoscopy. When the spinal cord can fluctuate gently without effort, it means that the decompression has been fully completed. We therefore recommend protecting the osseous structure and not exceeding half of the articular process to avoid iatrogenic postoperative spinal instability.

The shortcoming of this study is the number of patient samples is small, and a large sample study should be carried out jointly with multiple centers for verification.

\section{Conclusions}

TE-ULBD is safe and effective for TOLF. Minimally invasive surgery of the spine can effectively complement conventional open surgery, and has the advantages of minimal surgical trauma, reduced bleeding, less postoperative pain, faster convalescence, and short hospitalization time.

\section{Acknowledgments}

Funding: This work was partially supported by a grant from National Natural Science Foundation of China (No. 82004385 to YPL), Natural Science Foundation of Guangdong Province of China (No. 2019A1515011916 to YPL) and the Guangdong Province High-level University Construction Project (No. A3-0402-20-415-049 to BLC).

\section{Footnote}

Reporting Checklist: The authors have completed the STROBE reporting checklist. Available at https://dx.doi. org/10.21037/atm-21-2181

Data Sharing Statement: Available at https://dx.doi. org/10.21037/atm-21-2181

Conflicts of Interest: All authors have completed the ICMJE uniform disclosure form (available at https://dx.doi. org/10.21037/atm-21-2181). The authors have no conflicts of interest to declare.

Ethical Statement: The authors are accountable for all aspects of the work in ensuring that questions related to the accuracy or integrity of any part of the work are appropriately investigated and resolved. The study was conducted in accordance with the Declaration of Helsinki (as revised in 2013). The present study as approved by the Ethics Committee of the Guangdong Provincial Hospital of Chinese Medicine (No.: YE2021-146-01), and written informed consent was obtained from all participants.

Open Access Statement: This is an Open Access article distributed in accordance with the Creative Commons Attribution-NonCommercial-NoDerivs 4.0 International License (CC BY-NC-ND 4.0), which permits the noncommercial replication and distribution of the article with the strict proviso that no changes or edits are made and the 
original work is properly cited (including links to both the formal publication through the relevant DOI and the license). See: https://creativecommons.org/licenses/by-nc-nd/4.0/.

\section{References}

1. Lee BJ, Park JH, Jeon SR, et al. Clinically significant radiographic parameter for thoracic myelopathy caused by ossification of the ligamentum flavum. Eur Spine J 2019;28:1846-54.

2. Pascal-Moussellard H, Cabre P, Smadja D, et al. Symptomatic ossification of the ligamentum flavum: a clinical series from the French Antilles. Spine (Phila Pa 1976) 2005;30:E400-5.

3. Inamasu J, Guiot BH. A review of factors predictive of surgical outcome for ossification of the ligamentum flavum of the thoracic spine. J Neurosurg Spine 2006;5:133-9.

4. Kim DH, Lee SH, Lee JS, et al. High thoracic ossification of ligamentum flavum causing partial Horner syndrome. Br J Neurosurg 2021;35:231-2.

5. Aizawa T, Sato T, Sasaki H, et al. Thoracic myelopathy caused by ossification of the ligamentum flavum: clinical features and surgical results in the Japanese population. J Neurosurg Spine 2006;5:514-9.

6. Onishi E, Yasuda T, Yamamoto H, et al. Outcomes of Surgical Treatment for Thoracic Myelopathy: A Singleinstitutional Study of 73 Patients. Spine (Phila Pa 1976) 2016;41:E1356-63.

7. Ahn DK, Lee S, Moon SH, et al. Ossification of the ligamentum flavum. Asian Spine J 2014;8:89-96.

8. Miyakoshi N, Shimada Y, Suzuki T, et al. Factors related to long-term outcome after decompressive surgery for ossification of the ligamentum flavum of the thoracic spine. J Neurosurg 2003;99:251-6.

9. Li Z, Ren D, Zhao Y, et al. Clinical characteristics and surgical outcome of thoracic myelopathy caused by ossification of the ligamentum flavum: a retrospective analysis of 85 cases. Spinal Cord 2016;54:188-96.

10. Wang CH, Cui WL, Xue JL, et al. Transforaminal en bloc resection for the treatment of thoracic ossification of the ligamentum flavum: Retrospective cohort study. Int J Surg 2018;54:278-84.

11. Nishiura I, Isozumi T, Nishihara K, et al. Surgical approach to ossification of the thoracic yellow ligament. Surg Neurol 1999;51:368-72.

12. Park BC, Min WK, et al. Surgical outcome of thoracic myelopathy secondary to ossification of ligamentum flavum. Joint Bone Spine 2007;74:600-5.
13. Akhaddar A, Mansouri A, Zrara I, et al. Thoracic spinal cord compression by ligamentum flavum ossifications. Joint Bone Spine 2002;69:319-23.

14. Chen XQ, Yang HL, Wang GL, et al. Surgery for thoracic myelopathy caused by ossification of the ligamentum flavum. J Clin Neurosci 2009;16:1316-20.

15. Hou X, Chen Z, Sun C, et al. A systematic review of complications in thoracic spine surgery for ossification of ligamentum flavum. Spinal Cord 2018;56:301-7.

16. Liu L, Li Q, Ao J, et al. Posterior Percutaneous Endoscopic Technique Through Bilateral Translaminar Osseous Channels for Thoracic Spinal Stenosis Caused by Ossification of the Ligamentum Flavum Combined with Disk Herniation at the T10-11 Level: A Technical Note. World Neurosurg 2020;133:135-41.

17. Wu W, Diao W, Yang S, et al. The Effect of Using Visual Trepan to Treat Single-Segment Ossification of Ligamentum Flavum Under the Endoscope. World Neurosurg 2019;131:e550-6.

18. An B, Li XC, Zhou CP, et al. Percutaneous full endoscopic posterior decompression of thoracic myelopathy caused by ossification of the ligamentum flavum. Eur Spine J 2019;28:492-501.

19. Miao X, He D, Wu T, et al. Percutaneous Endoscopic Spine Minimally Invasive Technique for Decompression Therapy of Thoracic Myelopathy Caused by Ossification of the Ligamentum Flavum. World Neurosurg 2018;114:8-12.

20. Ruetten S, Hahn P, Oezdemir S, et al. Full-endoscopic uniportal decompression in disc herniations and stenosis of the thoracic spine using the interlaminar, extraforaminal, or transthoracic retropleural approach. J Neurosurg Spine 2018;29:157-68.

21. Xiaobing Z, Xingchen L, Honggang Z, et al. "U" route transforaminal percutaneous endoscopic thoracic discectomy as a new treatment for thoracic spinal stenosis. Int Orthop 2019;43:825-32.

22. Miyashita T, Ataka H, Tanno T. Spontaneous reduction of a floated ossification of the ligamentum flavum after posterior thoracic decompression (floating method); report of a case (abridged translation of a primary publication). Spine J 2013;13:e7-9.

23. Ning $S$, Chen Z, Fan D, et al. Genetic differences in osteogenic differentiation potency in the thoracic ossification of the ligamentum flavum under cyclic mechanical stress. Int J Mol Med 2017;39:135-43.

24. Nouri A, Martin AR, Mikulis D, et al. Magnetic resonance imaging assessment of degenerative cervical myelopathy: a 


\section{Page 10 of 10}

review of structural changes and measurement techniques. Neurosurg Focus 2016;40:E5.

25. Lee J, Satkunendrarajah K, Fehlings MG. Development and characterization of a novel rat model of cervical spondylotic myelopathy: the impact of chronic cord compression on clinical, neuroanatomical, and neurophysiological outcomes. J Neurotrauma 2012;29:1012-27.

26. Muthukumar N. Dural ossification in ossification of the ligamentum flavum: a preliminary report. Spine (Phila $\mathrm{Pa}$ 1976) 2009;34:2654-61.

27. Wang W, Kong L, Zhao H, et al. Thoracic ossification of ligamentum flavum caused by skeletal fluorosis. Eur Spine J 2007;16:1119-28.

28. Zhao Y, Xue Y, Shi N, et al. The CT and intraoperative observation of pedicel-ossification tunnel in 151 cases of thoracic spinal stenosis from ossification of ligamentum flavum. Eur Spine J 2014;23:1325-31.

Cite this article as: Lin YP, Lin R, Chen S, Rao SY, Zhao S, Wen T, Wang HS, Hu WX, Liu BX, Li XY, Li YJ, Chen BL. Thoracic full-endoscopic unilateral laminotomy with bilateral decompression for treating ossification of the ligamentum flavum with myelopathy. Ann Transl Med 2021;9(12):977. doi: 10.21037/atm-21-2181

\section{Lin et al. TE-ULBD for treating ossification of the ligamentum flavum}

29. Ikuta K, Tarukado K, Senba H, et al. Decompression procedure using a microendoscopic technique for thoracic myelopathy caused by ossification of the ligamentum flavum. Minim Invasive Neurosurg 2011;54:271-3.

30. Baba S, Oshima Y, Iwahori T, et al. Microendoscopic posterior decompression for the treatment of thoracic myelopathy caused by ossification of the ligamentum flavum: a technical report. Eur Spine J 2016;25:1912-9.

31. Wang Y, Yang L, Lei T, et al. Benefits and Risks of Subsection Laminectomy with Pedicle Screw Fixation for Ossification of the Ligamentum Flavum of the Thoracic Spine: A Retrospective Study of 30 Patients. Med Sci Monit 2019;25:6341-50.

32. Gibson RDS, Wagner R, Gibson JNA. Full endoscopic surgery for thoracic pathology: an assessment of supportive evidence. EFORT Open Rev 2021;6:50-60.

(English Language Editor: R. Scott) 